\title{
Relationship of ER, PR, HER2 / neu with Other Prognostic Factors in Breast Cancer along with the Role of Androgen Receptor in Triple Negative Breast Cancer
}

\author{
Arshi Khan¹, Reeni Malik², Pramila Jain³, Deepshikha Verma ${ }^{4}$, Vedanti Newasker ${ }^{5}$ \\ 1, 2, 3, 4, 5 Department of Pathology, Gandhi Medical College, Bhopal, Madhya Pradesh, India
}

\section{ABSTRACT}

\section{BACKGROUND}

Understanding various risk factors associated with breast cancer can help in early identification \& prompt treatment of patients with breast cancer. Apart from clinical parameters like age, disease presentation and menopausal status, important prognostic indicators in histopathology are size and extent of tumour, histologic type, histologic grade and lymph node status. Also, there are other factors which are not only predictive of outcome, but also direct therapies against particular molecular targets. These factors are oestrogen receptor (ER) status, progesterone receptor (PR) status, HER2 / neu status, Ki-67 proliferation index \& androgen receptor (AR) status. We wanted to analyse various hormone receptors \& their correlation with prognostic factors. In addition, androgen receptor expression is also studied in triple negative breast cancer cases.

\section{METHODS}

The study included 50 cases over a period of 18 months from January 2018 to June 2019 received in the Department of Pathology, Gandhi Medical College, Bhopal, India. These cases were subjected to histopathological \& immunohistochemistry (IHC) evaluation.

\section{RESULTS}

Among the 50 cases studied, the most common subtype was infiltrating ductal carcinoma (NOS - no special type, $84 \%$ ). Majority of patients were ER, PR, HER2 / neu negative ( $48 \%$ ) and among those triple negative cases, $25 \%$ of cases were androgen receptor positive.

\section{CONCLUSIONS}

Expression of the hormone receptor (ER and PR) and HER2 status may provide significant information in directing patient management. Since traditional pathological methods and IHC remain standard for guiding the use of treatment, clinicians may be challenged with equivocal results that directs towards additional testing for definitive diagnosis and, better patient outcome. The most used therapy for advanced breast cancers is based on the use of AR antagonists, such as bicalutamide and enzalutamide, first- and second-generation AR antagonists respectively. Gene signatures, bioinformatics, and other clinical trials are also beneficial for clinician in estimating the benefits expected from adjuvant chemotherapy.

\section{KEY WORDS}

Breast Cancer, Oestrogen Receptor, Androgen Receptor, Triple Negative

\author{
Corresponding Author: \\ Dr. Pramila Jain, \\ Department of Pathology, \\ Gandhi Medical College, \\ Madhya Pradesh, \\ Bhopal, India. \\ E-mail: prmila8560@gmail.com
}

DOI: $10.14260 /$ jemds/2021/116

How to Cite This Article:

Khan A, Malik R, Jain P, et al. Relationship of $E R, P R, H e r 2 /$ neu with other prognostic factors in breast cancer along with role of androgen receptor in triple negative breast cancer. J Evolution Med Dent Sci 2021;10(08):536-540, DOI: $10.14260 /$ jemds/2021/116

Submission 23-07-2020,

Peer Review 30-12-2020,

Acceptance 06-01-2021,

Published 22-02-2021.

Copyright (C) 2021 Arshi Khan et al. This is an open access article distributed under Creative Commons Attribution License [Attribution 4.0 International (CC BY 4.0)] 


\section{BACKGROUND}

Breast carcinoma is the most common malignant tumour and second most common cancer overall. There were over more than 2.1 million cases occurring worldwide annually (according to WHO-World Health Organization 2019 statistics). It is the leading cause of carcinoma death in women. ${ }^{1}$

The spectrum of malignant breast lesion includes ductal carcinoma, lobular carcinoma, medullary carcinoma, metaplastic carcinoma, secretory carcinoma papillary carcinoma. Incidence for these malignant lesions increases after menopause. These histological variations influence the clinical presentation, biological behaviour \& therapeutic response to a varying extent. Based on these morphological variations, several classifications have been developed over the years to guide for proper therapeutic management of these pateints. ${ }^{2}$

A crucial development in treatment of breast carcinoma was recognition that the presence of hormone receptors (ER \& $\mathrm{PR}$ ) in tumour tissue, correlates well with response to hormone therapy (lowers the hormone levels or block hormone receptor) and chemotherapy. These are called as hormone receptor-positive breast cancer cells, which grows more slowly than hormone receptor-negative cancer cells \& usually has good prognosis in the short-term.

Hormone receptor-negative breast cancers, also known as triple-negative breast cancer, as the name implies, they are negative for either of hormone receptors (ER, PR, HER2 / neu). So, treatment with hormone therapy is not useful. Also, they are more common in women who have not yet achieved menopause. For these, chemotherapy can still be useful. ${ }^{3}$

Triple-positive cancers are (ER, PR and HER2-positive) can be treated with hormone drugs as well as drugs which target HER2 protein. ${ }^{3}$

ER \& PR are co-dependent variables. The presence of ER and PR hormone receptors are correlated with a better outcome, though PR being a weaker predictor of response to endocrine therapy than ER. ER positive tend to be better differentiated tumours conversely ER negative tend to have grade 3 histology

Identification of HER2 / neu tumours is critically important in selecting patients for HER2 / neu targeted therapies, such as trastuzumab (Herceptin). HER2 / neu overexpression is associated with poor prognosis.

The androgen receptor (AR) is a proven clinical target in carcinoma prostate. Recent research says that it is an emerging hormonal target in breast cancer as well, with clinical benefit in both oestrogen receptor (ER) positive and negative tumours. ${ }^{4}$ The presence of AR receptors is associated with poorer survival in stage III triple negative breast cancer (TNBC) in comparison with those at earlier stages. ${ }^{3}$

The most useful therapy for advanced breast cancers (tamoxifen resistant breast cancers and TNBCs) is based on the use of molecular target androgen receptors and so AR antagonists, such as bicalutamide and enzalutamide. Both the antagonists have been used in clinical trials with positive results. ${ }^{5}$

We wanted to evaluate histopathological spectrum and its correlation with hormone receptors of breast cancer patients attending the pathology department at GMC Bhopal, India.

\section{METHODS}

The study included prospective as well as retrospective cases over a period of 18 months from January 2018 to June 2019 in Department of Pathology, Gandhi Medical College, Bhopal, India. This study has been done as per standard ethics \& by maintaining confidentiality of patient information. The study was approved by ethics committee.

Total 50 cases were studied which included lumpectomy, simple mastectomy, modified radical mastectomy as well as biopsy specimens. These specimens were fixed in $10 \%$ formalin solution for $24 \mathrm{hrs}$. Detailed gross examination of all received specimens was carried out for tumour size, location \& nodal metastases. Then tissue was submitted for processing and paraffin embedded tissue were cut and stained routinely by haematoxylin \& eosin stain and reported.

All cases were histologically graded according to Modified Bloom Richardson Elston grading system. ${ }^{6}$ (Table 1) After that, breast cancer tissue blocks were selected for IHC evaluation. Representative sections of tumour were processed for ER, PR, HER-2 / neu and AR immunohistochemical staining. Normal breast tissue was taken as internal positive control. Sections were taken on poly L lysine coated slides. Antigen retrieval was done by citrate buffer and slides were stained with monoclonal antibodies against ER, PR, HER-2 / neu and AR receptors. The results were screened and interpreted according to published guidelines by The American Society of Clinical Oncology \& The College of American Pathologist (ASCO / CAP).7,8

Interpretation of HER2 / neu staining is done by membranous staining (Table 2).

\begin{tabular}{|c|c|c|}
\hline & Features & Score \\
\hline \multirow{3}{*}{ Tubule and gland formation } & Majority of tumour > $75 \%$ & 1 \\
\hline & Moderate degree $10-75 \%$ & 2 \\
\hline & Little or none $<10 \%$ & 3 \\
\hline \multirow{3}{*}{ Nuclear pleomorphism } & Small, regular uniform cells & 1 \\
\hline & $\begin{array}{l}\text { Moderate increase in size and } \\
\text { variability }\end{array}$ & 2 \\
\hline & Marked variation & 3 \\
\hline Mitotic counts & Dependent of microscopic field area & $1-3$ \\
\hline \multirow{3}{*}{$\begin{array}{l}\text { Mitotic count / } 10 \text { high } \\
\text { power fields }\end{array}$} & 1 point & $0-9$ \\
\hline & 2 points & $10-19$ \\
\hline & 3 points & $>20$ \\
\hline \multicolumn{3}{|c|}{$\begin{array}{l}\text { Table 1. Semi-Quantitative Method for Assessing } \\
\text { Histological Grade in Breast from Elston and Ellis } \\
\text { Modified Scarff-Bloom-Richardson Scoring System** }\end{array}$} \\
\hline
\end{tabular}

\begin{tabular}{|c|c|c|}
\hline $\begin{array}{l}\text { HER2 IHC } \\
\text { Score }\end{array}$ & Staining Pattern & $\begin{array}{l}\text { HER2 Protein } \\
\text { Expression }\end{array}$ \\
\hline 0 & No reactivity seen & Negative \\
\hline 1 & $\begin{array}{l}\text { Weak incomplete membrane staining in any } \\
\text { proportion of tumour cells }\end{array}$ & Negative \\
\hline 2 & $\begin{array}{c}\text { Non uniform or weak to moderate complete } \\
\text { membranous reactivity in }>10 \% \text { of tumour } \\
\text { cells or intense complete staining of }<30 \% \text { of } \\
\text { the invasive tumour cells }\end{array}$ & Equivocal \\
\hline 3 & $\begin{array}{l}\text { Uniform, intense, complete membranous } \\
\text { reactivity in }>30 \% \text { of the invasive tumour } \\
\text { cells. }\end{array}$ & Positive \\
\hline \multicolumn{3}{|c|}{ Table 2. Interpretation of HER2 / neu Staining } \\
\hline
\end{tabular}

\section{Statistical Analysis}

Statistical analysis was done using IBM SPSS software version 24. Simple percentages were graphed against various parameters and report analysed. 


\section{RESULTS}

The age of the patients ranged from 20 to 88 years. 13 out of 50 patients $(26.0 \%)$ had tumour size less than or equal to 4 cms. The most common histologic type of breast carcinoma was invasive ductal carcinoma (NOS). 45 patients out of total $50(75 \%)$ had invasive ductal carcinoma (IDC) (NOS) type. Majority of tumours were predominantly of histopathological grade 2 (72\%). $74 \%$ (37 patients out of 50 ) presented with lymph node metastasis.

In present study it was observed that grade I tumours are $72.7 \%$ triple negative, $18 \%$ are ER / PR positive and $9 \%$ are HER2+. In grade 2 tumours, $64.7 \%$ are triple negative, $5.8 \%$ HER2+ and $29.4 \%$ ER / PR positive. In grade 3 tumours 71.4 $\%$ are triple negative and $14.2 \%$ are ER and PR positive as well HER2 positive. No cases were found to be of grade 0 . (Graph 1)

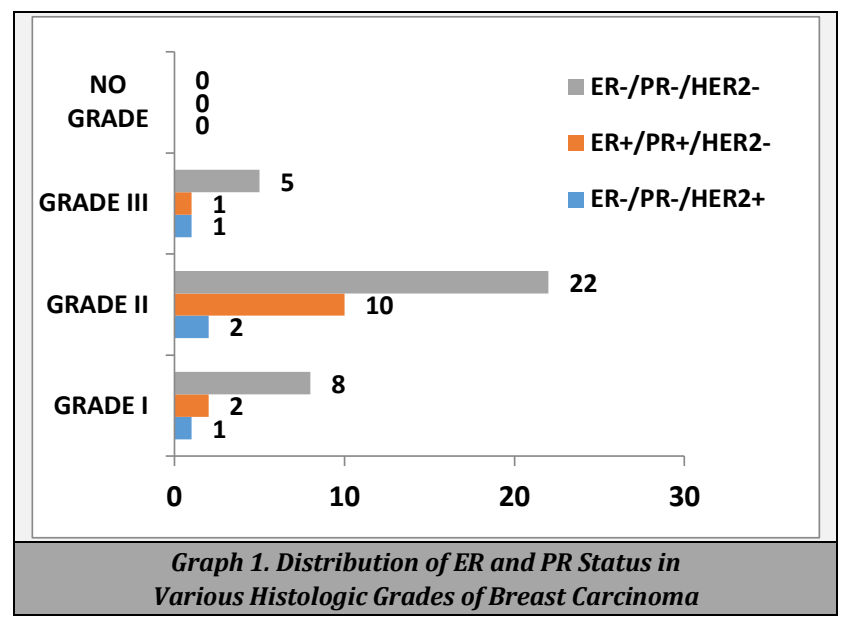

In our present study, no patient showed ER, PR and HER2 positivity, 11 patients out of 50 (22\%) showed ER, PR negative and HER2 positive, whereas 15 out of 50 (30\%) showed ER, PR positive but HER2 negative. Remaining 24 out of 50 (48\%) patients showed ER, PR, HER2 negative. Based on these triple negative cases, we further proceeded with applying androgen receptor on same. (Graph 2).

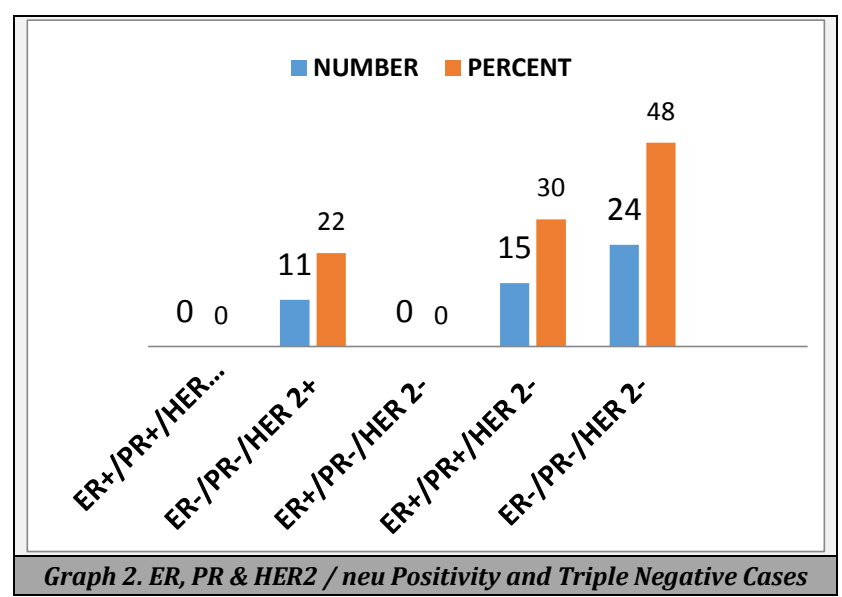

Majority of cases with lymph node metastasis were triple negative (68.4\%). Majority of grade 2 tumours were in the age group of 40 - 49 yrs. followed by the age group of 50 - 59 yrs. Majority of tumours in the present study were triple negative (70.0\%). Both cases less than 30 yrs. were triple negative. 52.3
$\%$ of cases in the age group of 40 - 49 yrs. were triple negative. Also $34.6 \%$ of cases in the age group of 40 - 49 yrs. were triple negative. As the age increase majority of tumours were ER and PR positive and HER2 / neu (luminal A) followed by luminal B patients (triple positive).

- 6 cases out of 24 cases (25\%) are androgen receptor positive whereas 18 cases out of 24 were androgen receptor negative which constitutes $75 \%$. (Pie-Chart).

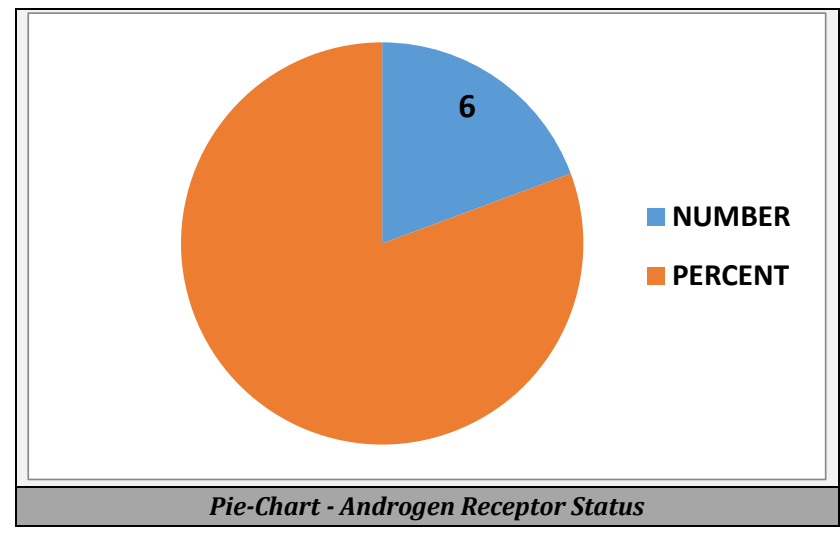

DISCUSSION

The current study was done to assess if histopathological methods can be aided by immunohistochemical markers like ER, PR and HER2 / neu, AR in predicting the response to hormone therapy and neoadjuvant chemotherapy. Total 50 cases of modified radical mastectomy specimens over a period of 18 months from January 2018 to June 2019 received in Department of Pathology, Gandhi Medical College, Bhopal, India, for breast cancer were evaluated by light microscopy to determine the histological type and immunohistochemistry was done to find out the ER, PR, HER2 / neu \& AR status of the tumour.

Oestrogen receptor determinations have significantly improved the predictability of response to endocrine therapy in advanced breast cancer. Patients with ER+ have a $50 \%$ and $60 \%$ probability of response to endocrine manipulation.

Premenopausal women were treated with a selective oestrogen receptor modulator, like tamoxifen. Postmenopausal women were treated with an aromatase inhibitor like Arimidex. Both treatments starve the cancer cells of oestrogen so they can 't grow.

\section{Histologic Subtype of Breast Carcinoma}

Among subtypes, in invasive ductal carcinoma ER, PR, HER2 neu is positive in $30 \%(\mathrm{~N}=50)$ cases, while ER, PR, HER2 neu is negative in $70 \%(\mathrm{~N}=50)$ cases. In lobular carcinoma ER, $P R$, HER2 neu is positive in $33 \%(\mathrm{~N}=50)$ cases, while ER, PR, HER2 neu is negative in $66 \%(\mathrm{~N}=50)$ cases. In mucinous ER, $\mathrm{PR}, \mathrm{HER} 2 \mathrm{neu}$ is positive in $65 \%(\mathrm{~N}=50)$ cases, while ER, PR, HER2 neu is negative in $35 \%(\mathrm{~N}=50)$ cases. In medullary carcinoma ER, PR, HER2 neu is positive in $44 \%(\mathrm{~N}=50)$ cases, while ER, PR, HER2 neu is negative in $56 \%(\mathrm{~N}=50)$ cases. These studies were consistent with study by Rao c, Shetty J et al., ${ }^{9}$ while the studies done by Cherry Bansal, Aarti Sharma et al., ${ }^{10}$ showed lesser number of triple negative cases (23\%). 


\section{Lymph Node Status}

In the present study axillary lymph node metastasis were present in $68 \%$ (34 patients out of 50) cases. Majority of the cases with lymph node metastasis, $46 \%(\mathrm{~N}=50)$ were triple negative, while $16 \%(\mathrm{~N}=50)$ are ER, PR positive and HER2 negative, whereas $18 \%(\mathrm{~N}=50)$ are ER, PR negative and HER2 positive. This finding was in concordance with other studies also while inverse relationship was found in studies done by Chakarborty A, Bose Ck et al. ${ }^{11}$

Cases without lymph node metastasis are mainly $90 \%(\mathrm{~N}$ $=50)$ triple negative, while $04 \%(\mathrm{~N}=50)$ are $\mathrm{ER}, \mathrm{PR}$ positive and HER2 negative whereas $6 \%(\mathrm{~N}=50)$ are ER, PR negative and HER2 positive.

The survival rate depends on level of axillary node involved (low, medium, high), the absolute number, the amount of metastatic tumour \& presence or absence of extranodal extension.

\section{Grade of Tumour}

In the present study grade 2 was most common $40 \%(N=50)$ followed by grade 1 and grade 3 . In present study it is observed that grade I tumours are mostly $72 \%(\mathrm{~N}=50)$ triple negative, $18 \%(\mathrm{~N}=50)$ are ER, PR positive and HER2 negative whereas $9 \%(\mathrm{~N}=50)$ are ER, PR negative and HER2 positive. In grade II tumours $64 \%(\mathrm{~N}=50)$ are triple negative, $5.8 \%(\mathrm{~N}=50)$ are ER, PR positive and HER2 negative whereas $29 \%(\mathrm{~N}=50)$ are ER, PR negative and HER2 positive. In grade III tumours $71.4 \%(\mathrm{~N}=50)$ are triple negative, $14.5 \%(\mathrm{~N}=50)$ are ER, PR positive and HER2 negative whereas $14.5 \%(\mathrm{~N}=50)$ is ER, PR negative and HER2 positive.

In present study, IHC was used to measure protein expression levels of biomarkers like ER, PR and HER2 / neu in 50 cases of breast cancer which were divided into two groups triple negative (TNBC) and non-triple negative (non-TNBC). In this study non triple negative tumours are the most commonly occurring subtype. Lack of significant association between these subtypes and their clinical and pathological behaviour could be due to the small sample size. In the present study among triple negative cases, androgen receptor was positive in $25 \%(\mathrm{~N}=50)$ of cases. Bianchini G, Balko JM found $33 \%$ (N $=70)$, Mayer IA found $26 \%(\mathrm{~N}=100)$ of triple negative cases were androgen receptor positive. ${ }^{12}$ While Green AR et al. found $75 \%(\mathrm{~N}=100)$, Tan $\mathrm{W}$ et al. found $63 \%(\mathrm{~N}=214)$ higher androgen receptor positivity,13,14 as compared to the present study.

\section{CONCLUSIONS}

Expression of the hormone receptor (ER and PR) and HER2 status may provide significant information in directing patient management and response to hormonal and biological agents. Oestrogen receptor expression is the main indicator of potential responses to endocrine therapy. The use of hormonal therapy in breast cancer has seriously improved the overall outcome for patients with early stage hormone receptor positive breast cancer.

The androgen receptor is an emerging and promising target in breast cancer especially in TNBC subtype, both because of the lack of a well-established targetable feature (ER
\& PR) and the presence of a solid molecular subtype with different prognosis.

Gene signatures from gene expression analysis, bioinformatics, and other clinical trials can now help the clinician in estimating the benefits expected from systemic adjuvant chemotherapy.

Data sharing statement provided by the authors is available with the full text of this article at jemds.com.

Financial or other competing interests: None.

Disclosure forms provided by the authors are available with the full text of this article at jemds.com.

\section{REFERENCES}

[1] National Cancer Registry Programme, Indian Council of Medical Research 2001-2004. Incidence and distribution of cancer. Banglore, India Coordinating Unit (ICMR) 2006:8-30.

[2] Simpson PT, Reis-Filho JS, Gale T, et al. Molecular evolution of breast cancer. J Pathol 2005;205(2):248-54.

[3] Woodsen RVD. The problem prevelance of breast cancer. Philippines 2010:120-4.

[4] Pollán M. Epidemiology of breast cancer in young women. Breast Cancer Res Treat 2010;123(Suppl 1):3-6.

[5] Bianchini G, Balko JM, Mayer IA, et al. Triple-negative breast cancer: challenges and opportunities of a heterogeneous disease. Nat Rev Clin Oncol 2016;13(11):674-90.

[6] Elston CW, EIlis IO. Pathological prognostic factors in breast cancer. The value of histological grade in breast cancer: experience from a large study with long-term follow up. Histopathology 1991;19(5)403-10.

[7] Fitzgibbons PL, Murphy DA, Hammond MEH, et al. Recommendations for validating estrogen and progesterone receptor immunohistochemistry assays. Arch Pathol Lab Med 2010;134(6):930-5.

[8] Hammond MEH, Hayes DF, Dowsett M, et al. American society of clinical oncology/college of American pathologists guideline recommendations for immunohistochemical testing of estrogen and progesterone receptors in breast cancer. J Clin Oncol 2010;28(16):2784-95.

[9] Rao C, Shetty J, Prasad HLK. Morphological profile and receptor status in breast carcinoma: an institutional study. J Can Res Ther 2013;9(1):44-9.

[10] Bansal C, Sharma A, Pujani M, et al. Correlation of hormone receptor and human epidermal growth factor receptor $-2 /$ neu expression in breast cancer with various clinicopathologic factors. Indian J Med Paediatr Oncol 2017;38(4):483-9.

[11] Chakarborty A, Bose CK, Basak J, et al. Determinants of lymph node status in women with breast cancer: a hospital based study from Eastern India. Indian J Med Res 2016;143(Suppl 1):S45-51.

[12] Yeh S, Hu Y, Wang P, et al. Abnormal mammary gland development and growth retardation in female mice and MCF7 breast cancer cells lacking androgen receptor. J Exp Med 2003;198(12):1899-908. 
[13] Honma N, Horii R, Iwase T, et al. Clinical importance of estrogen receptor-beta evaluation in breast cancer patients treated with adjuvant tamoxifen therapy. J Clin Oncol 2008;26(22):3727-34.
[14] Anestis A, Karamouzis MV, Dalagiorgou G, et al. Is androgen receptor targeting an emerging treatment strategy for triple negative breast cancer? Cancer Treat Rev 2015;41(6):547-53. 